Shakespeare et le monde animal

\title{
Introduction
}

\section{François Laroque}

\section{(2) OpenEdition \\ Journals}

Édition électronique

URL : http://journals.openedition.org/shakespeare/5828

DOI : 10.4000/shakespeare.5828

ISSN : 2271-6424

Éditeur

Société Française Shakespeare

\section{Référence électronique}

François Laroque, «Introduction », Actes des congrès de la Société française Shakespeare [En ligne], 38 2020, mis en ligne le 17 juillet 2020, consulté le 22 juillet 2020. URL : http://journals.openedition.org/ shakespeare/5828; DOI : https://doi.org/10.4000/shakespeare.5828

Ce document a été généré automatiquement le 22 juillet 2020.

(c) SFS 


\title{
Introduction
}

\author{
François Laroque
}

1 Dans le titre d'un livre écrit en 1973, Terence Hawkes évoquait « les animaux parlants de Shakespeare ». Si la question du langage et de la communication est évidemment centrale, elle est loin d'être le seul trait que le dramaturge retient pour différencier l'homme de l'animal dans son œuvre. Ce fils de gantier d'une petite ville de province qui a, dans sa jeunesse, nécessairement assisté à l'abattage et à la souffrance des bêtes, tout en étant par ailleurs initié au processus de traitement des peaux et autres matières animales, a certainement vécu là une expérience personnelle forte et a ainsi dû attacher une attention particulière à ce monde des animaux.

2 Les animaux sont en effet au cœur du corpus shakespearien, à la fois par leur présence scénique (on pense à Crab, le chien de Lance, dans Les Deux gentilshommes de Vérone ou encore à l'ours du Conte d'hiver), et par leur évocation du monde médiéval de l'héraldique et des bestiaires, de la chasse et du sacrifice. Les historiae animalium d'Aristote, de Pline l'Ancien comme celles de Conrad Gesner et de Topsell, les livres d'emblèmes représentant de nombreux animaux, ont fourni à Shakespeare et à ses collègues dramaturges un vaste répertoire d'images, de proverbes, voire de petites fables ironiques. Quant aux Métamorphoses d'Ovide, elles se retrouvent dans l'âne Bottom, le loup Shylock ainsi que chez un Orsino qui se compare à Actéon, mais aussi à propos des chiens d'assassins convoqués par Macbeth, des filles pélicans de Lear ou encore de Caliban, l'homme poisson de La Tempête. Aux dires de Iago, Desdémone et Othello "font la bête à deux dos » et menacent de produire toute une engeance de monstres. Mais aussi bien le théâtre, jeu de masques et de déguisements, favorise de telles métamorphoses, qu'il s'agisse de faire rire, d'effrayer ou de donner à penser, comme avec la face de chien de De Florès (La Tragédie de l'échange de Middleton) ou les noms-sobriquets animaliers des personnages du Volpone de Ben Jonson.

3 Alors, l'homme est-il ce "parangon des animaux" ainsi qu'Hamlet le déclare à Rosencrantz et Guildenstern dans un moment d'ironie amère ? Car, outre une vraie compassion pour les bêtes à l'âme sensitible, pour la bête malheureuse qui sert à illustrer la mélancolie ou le taedium vitae, les animaux sont aussi présentés comme autant de modèles possibles pour l'homme. Aux yeux de l'archevêque de Canterbury, 
les abeilles «enseignent / La pratique de l'ordre au peuple du royaume» (Henri V) tandis que toute la beauté et la noblesse d'Antoine se résument pour Cléopâtre dans l'image du dauphin bondissant au-dessus de l'onde. Les contributions rassemblées dans la première partie du présent volume explorent la complexité et la variété de ces images à travers l'analyse de la dimension politique de l'hybridité humain-animal (Andreas Höefele) et des jeux de genre auxquels elle ouvre (Natália Pikli and Manon Turban).

4 La bête (le mot beast apparaît à 75 reprises dans l'œuvre de Shakespeare alors qu'elle ne comporte que huit occurrences pour le mot animal) se différencie bien sûr de l'animal qui, étymologiquement, renvoie au souffle de la vie (anima) qui produit le mouvement. Dès lors se pose la question de la domestication et du dressage et donc celle de l'opposition entre sociabilité et sauvagerie. Dans La Mégère apprivoisée, le Seigneur s'occupe avec amour de ses chiens au retour de la chasse, tandis qu'il est révolté par le spectacle donné par l'ivrogne sly: «Oh! la monstrueuse bête, il est vautré comme un porc». Shakespeare, comme toujours, se montre attentif à la singularité et à la diversité des individus plus qu'à l'espèce ou à la catégorie, et le monde animal donne lieu à la multiplication vertigineuse des appellations et à diverses acrobaties linguistiques. La deuxième section de ce numéro envisage précisément la façon dont les matières animales se donnent à voir ou entendre dans la chair linguistique du théâtre de la première modernité. Bruce Boerher relit les allusions à l'art de la chasse dans Comme il vous plaira (1598) pour en faire surgir la proximité avec la vision de l'environnement et des relations entre espèces que l'on retrouve dans les tragédies qui lui succèdent. La chasse se trouve également au cœur de l'analyse de Kevin Quarmby, qui sonde les termes de l'évocation des pratiques cynégétiques rurales dans 1 Henri IV, tandis que Jennifer Allport Reid se penche sur le discours du sacrifice et du cérémonial dans les tragédies romaines. L'article de Katherine Cox nous invite à entendre la façon dont les matériaux d'origine animale qui servaient la fabrication d'instruments de musique sont métaphoriquement réanimés par le théâtre et la poésie de Shakespeare. Florence Krésine nous donne ensuite à entendre et interroger la voix des animaux doués de parole que l'on rencontre notamment dans Beware the Cat de Baldwin.

La dernière partie de ce volume, consacrée aux métaphores bestiales, plonge au cœur de la culture visuelle et de la symbolique de l'animalité. Charlène Cruxent offre un aperçu de l'importance des animaux dans le Roméo et Juliette de Oh Tah-Suk en 1999, tandis que Nora Galland donne à penser la façon dont les références animales qui fondent certaines insultes font écho à des enjeux raciaux et sexuels. Jean-Jacques Chardin, enfin, revient sur la tradition emblématique et explore la façon dont la construction des images d'animaux dans les livres d'emblèmes les présente souvent de manière à ce que leur regard confronte directement celui du lecteur, afin de l'amener à une réflexion sur l'humain. 